\title{
Férula de estabilización preoperatoria en fracturas de fémur
}

https://doi.org/10.53358/ideas.v3i1.579

\author{
Ashtom Urbáez ${ }^{1}$, Simón Urbina ${ }^{1}$, Brizeida Ojeda ${ }^{2}$ \\ ${ }^{1}$ Centro de Biomecánica, Universidad de Carabobo, \\ Av. Universidad, Naguanagua, Estado Carabobo, Venezuela \\ 2 Departamento de Ingeniería Mecánica, EAFIT \\ Carrera $49 \mathrm{~N}^{\circ} 7$ Sur 50, Medellín, Colombia \\ 1uashtom@gmail.com,1seuluc@gmail.com,2bojedag@eafit.edu.co
}

\section{RESUMEN}

Uno de los métodos empleados para controlar el dolor, cuando un paciente ha sufrido una fractura a nivel de la diáfisis del fémur, es la tracción esquelética [1]. A continuación, se presentan los avances en el diseño de una férula de tracción para la estabilización preoperatoria en fracturas de fémur. Para ello se propuso una solución, dimensionada según las características antropométricas de pacientes adultos. Se seleccionó un material de uso hospitalario. El análisis de esfuerzos se llevó a cabo partiendo de la simulación de dos posiciones, en las cuales operará la férula durante su utilización. Para el cálculo numérico se empleó un programa basado en el Método de Elementos Finitos. Se obtuvieron resultados que garantizan la seguridad del dispositivo; así mismo, se verificaron los criterios establecidos en el marco del diseño, tales como la estabilidad del dispositivo, la ergonomía y la posibilidad de colocar la férula en diferentes posiciones.

Palabras Clave: Férula, Preoperatorio, Fractura, Fémur. 


\section{Introducción}

Las fracturas de miembro inferior generalmente son procesos clínicos que requieren soluciones quirúrgicas [2]. En países con crisis hospitalarias, el tiempo transcurrido entre el ingreso del paciente hasta que se realiza la intervención puede superar los 30 días, debido a la carencia de los insumos necesarios para llevar a cabo la cirugía. En estos casos se requiere inmovilizar el miembro afectado, con férulas, aplicando técnicas de tracción empleadas desde los inicios de la traumatología [3]. Una de las más conocidas es la férula de Braun, un dispositivo rígido, no regulable, que mantiene el miembro inferior elevado en la cama en posición funcional (semiflexión). Su uso es hospitalario, y está diseñada para el tratamiento de diferentes patologías del miembro inferior, entre las que se encuentran las fracturas de la cabeza y las diafisarias del fémur [4].

El uso más frecuente de este tipo de férulas es el tratamiento prequirúrgico de la fractura de fémur, ya que permite mantener el miembro inferior elevado logrando así aliviar el dolor y conseguir alineación de los huesos en caso de que los fragmentos óseos se encuentren fracturados [5].

En la actualidad, en hospitales públicos de Venezuela no se cuenta con los insumos necesarios para cubrir las demandas de las personas que asisten a los centros de salud. Esto implica un significativo desabastecimiento en cuanto a cualquier tipo de material hospitalario, incluyendo el requerido en el área de traumatología.

Dada la situación planteada el Centro de Biomecánica de la Universidad de Carabobo propone el diseño y construcción de una férula de Braun, con el propósito de que este dispositivo sea utilizado por los pacientes que lo requieran en los tratamientos preoperatorios de fracturas femorales. 


\section{Metodología}

\section{Fase 1: Recopilación de información}

En esta etapa se revisa la información referida a los métodos de estabilización de fractura, así como la anatomía de miembro inferior de pacientes adultos. El personal médico y de enfermería señalaron sus requerimientos basados en las situaciones que observan diariamente en los pacientes hospitalizados. Con las apreciaciones mencionadas se establecen las especificaciones del sistema a diseñar.

\section{Fase 2: Diseño de la férula de tracción}

Basados en la información de la fase previa se conciben características para la férula. Las mismas tienen que ver con la posición que adoptará el dispositivo para cumplir su función, la ergonomía y adaptabilidad a diferentes posiciones y longitudes de miembro inferior, un material que cumpla con las normas sanitarias, el peso que permita la movilización de un lugar a otro. Para dichos criterios se plantea la solución para la férula. Utilizando un software de diseño asistido por computadora se obtiene el modelo presentado en la Fig. 1. Cabe destacar que las tuberías con agujeros de la estructura base funcionan como reguladoras, tanto de los ángulos a los que se puede elevar el muslo para variar la altura de la pierna como de los ángulos para ejercer la tracción.

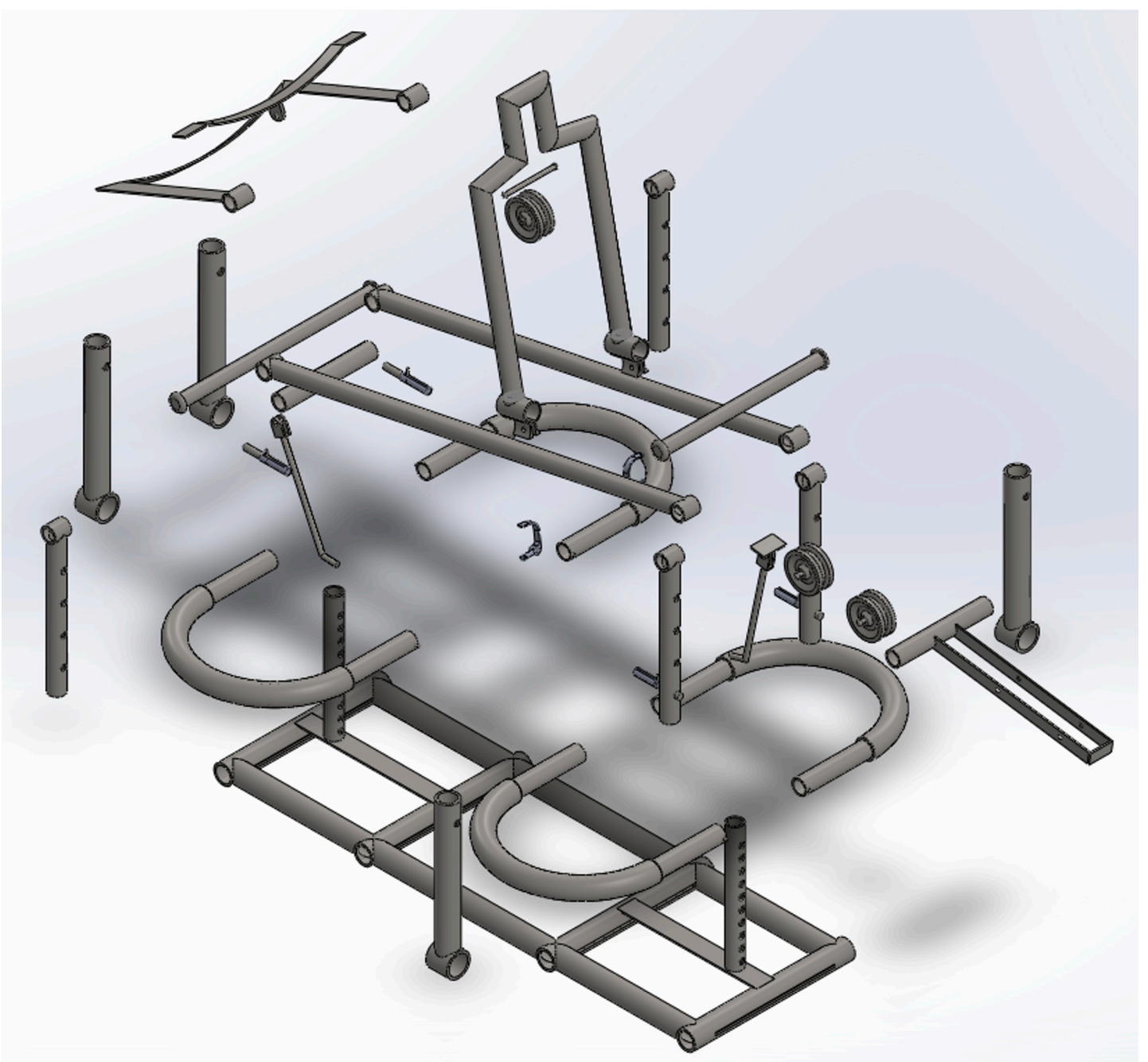

Fig. 1. Vista isométrica en explosión de la férula de tracción. 
Partiendo del modelo 3D se comprueba que es posible ensamblar los componentes de la férula (ver Fig. 2). Adicionalmente, se lleva a cabo la selección del material para la estructura de la férula. En esta fase se consideran la resistencia que ofrece el material, soldabilidad, disponibilidad en el mercado y uso hospitalario. En la Tabla 1 se indica la lista de componentes de la solución planteada para la férula.

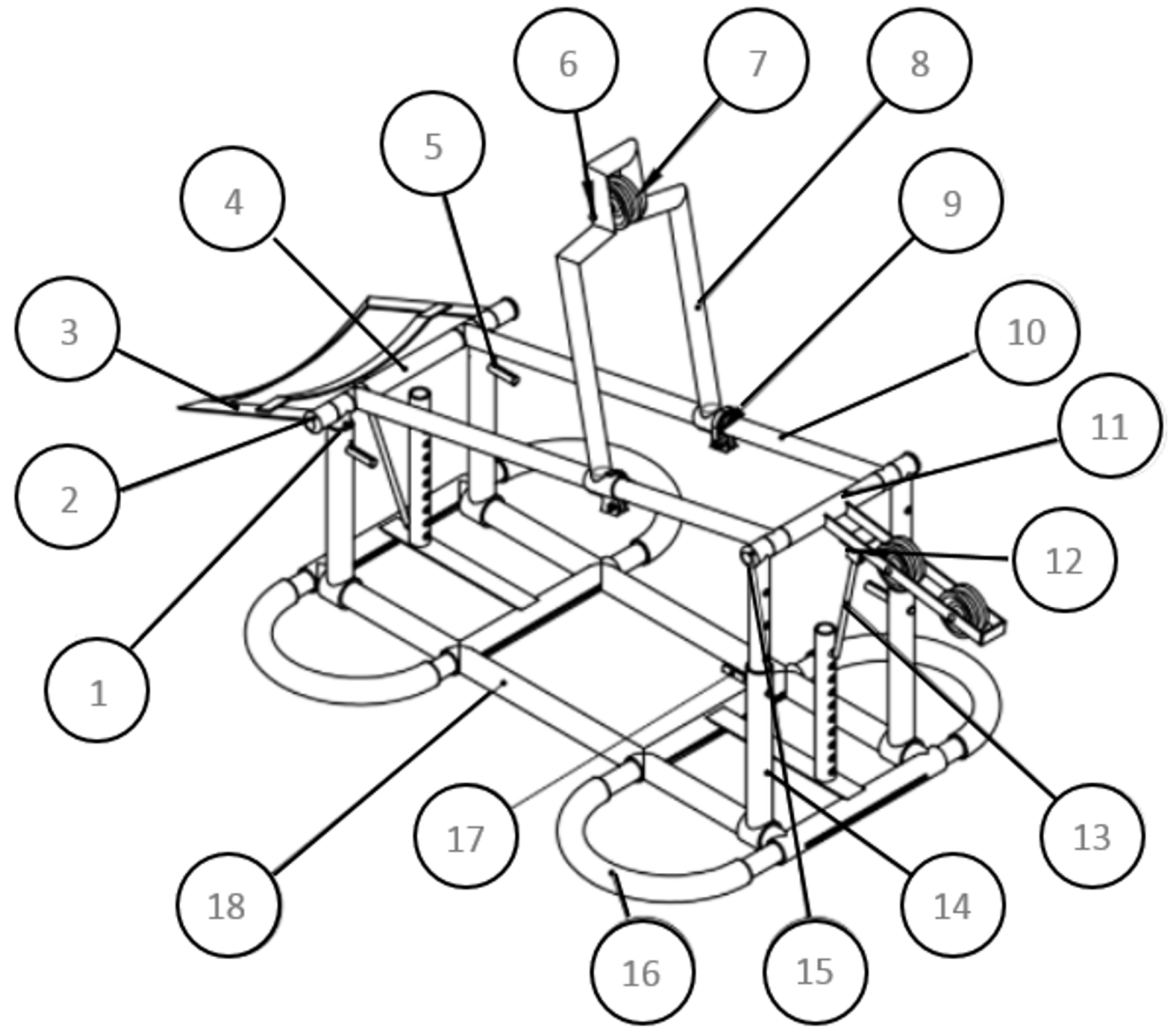

Fig. 2. Vista isométrica de la solución propuesta para la férula de tracción. 
Tabla 1. Lista de componentes de la solución planteada para la férula.

\begin{tabular}{|c|l|c|}
\hline No de Elemento & \multicolumn{1}{|c|}{ Descripción } & Cantidad \\
\hline 1 & Columnas superiores & 4 \\
2 & Eje posa muslo & 1 \\
3 & Posa muslo & 2 \\
4 & Tubería de protección del eje & 2 \\
5 & Pasador & 4 \\
6 & Pasador de poles & 1 \\
7 & Polea & 3 \\
8 & Campana & 1 \\
9 & Abrazadera & 2 \\
10 & Tubería para unión de columnas & 4 \\
11 & Base de poleas & 4 \\
12 & Pasador de gancho & 2 \\
13 & Gancho & 1 \\
14 & Columnas inferiores & 1 \\
15 & Eje de posa poleas & 1 \\
16 & Orejas & 1 \\
17 & Camisa de pasador & 1 \\
18 & Estructura base & \\
\hline
\end{tabular}

Respecto a los materiales para la férula, según las normas hospitalarias se recomienda para la construcción del dispositivo el acero inoxidable AISI/SAE 304, debido a que tiene una amplia gama de condiciones corrosivas. Adicionalmente es ventajoso porque posee buenas características para la soldadura. La resistencia a la corrosión es excelente. Las propiedades mecánicas del acero inoxidable 304 se encuentran especificadas en la Tabla 2.

Tabla 2. Propiedades mecánicas del Acero inoxidable AISI 304 [6]

\begin{tabular}{|c|c|c|}
\hline Propiedad & Valor & Unidad \\
\hline Esfuerzo de fluencia & 205 & $\mathrm{MPa}$ \\
\hline Esfuerzo máximo & 515 & $\mathrm{MPa}$ \\
\hline Elongación & $30 \%($ en $50 \mathrm{~mm})$ & -- \\
\hline Módulo de elasticidad & 190 & $\mathrm{GPa}$ \\
\hline Coeficiente de Poisson & 0,29 & --- \\
\hline Dureza & 201 & HBN \\
\hline
\end{tabular}

\section{Fase 3: Cálculos}

En esta fase se analizan las posiciones críticas que puede adoptar la férula. En la Fig. 3 (a) se observa la primera posición a la que puede colocarse la férula. La pantorrilla del paciente puede situarse sin ningún ángulo de elevación respecto a la horizontal, en caso de que eso sea lo que se necesite en el tratamiento; mientras que en la Fig. 3 (b) se observa la segunda posición a la que puede colocarse la férula. En este caso la pantorrilla del paciente se eleva respecto a respecto a la horizontal un ángulo determinado que dependerá del tratamiento a aplicar. 
La férula soporta el peso del miembro inferior de un paciente que es aproximadamente el $10 \%$ de su peso total. Para el diseño de esta férula se emplean las características de un adulto promedio: 1,75 m de estatura y $85 \mathrm{~kg}$ de masa. La tracción se puede aplicar progresivamente hasta un $15 \%$ del peso corporal [7].

La Fig. 4 muestra la distribución de cargas, que representan el apoyo de la tibia del paciente, de acuerdo con la posición inclinada de la férula. La flecha de color rojo representa el peso de la zona tibial junto con el pie del paciente $(6,4 \mathrm{~kg})$.

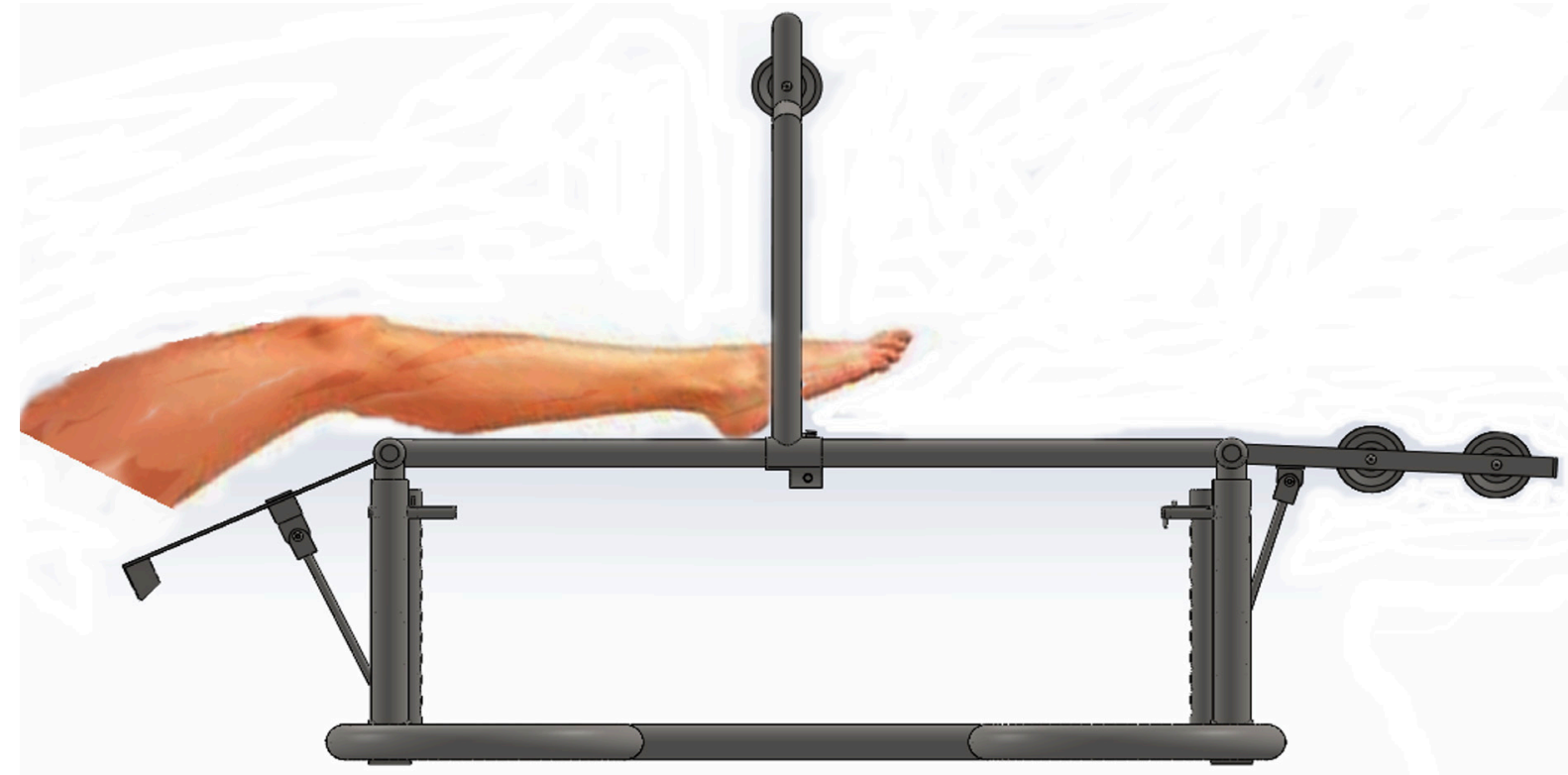

(a)

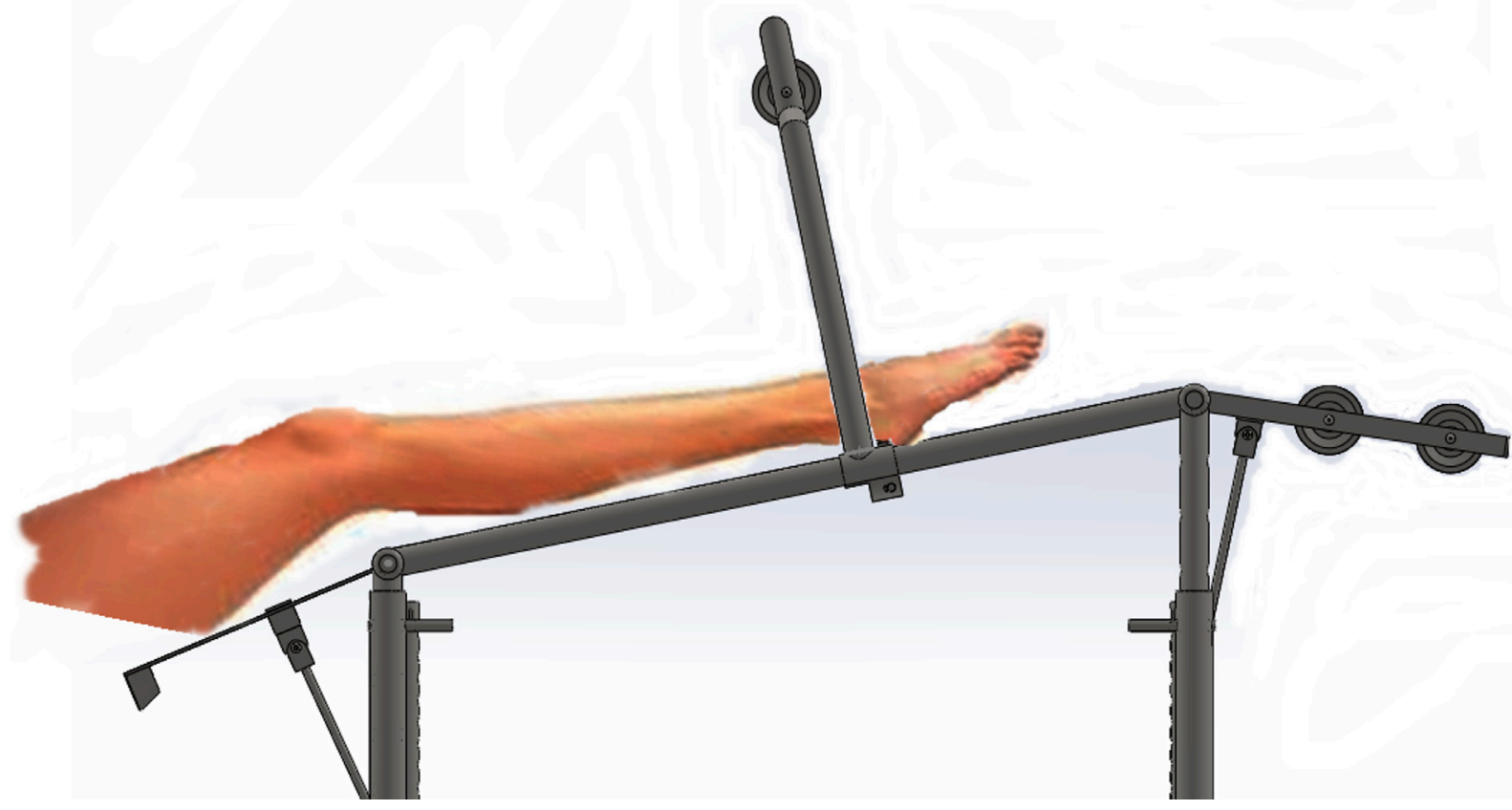

(b)

Fig. 3. Posiciones que puede adoptar la férula, (a) Posición Nro. 1 (Horizontal), (b) Posición Nro. 2 (con ángulo de inclinación). 


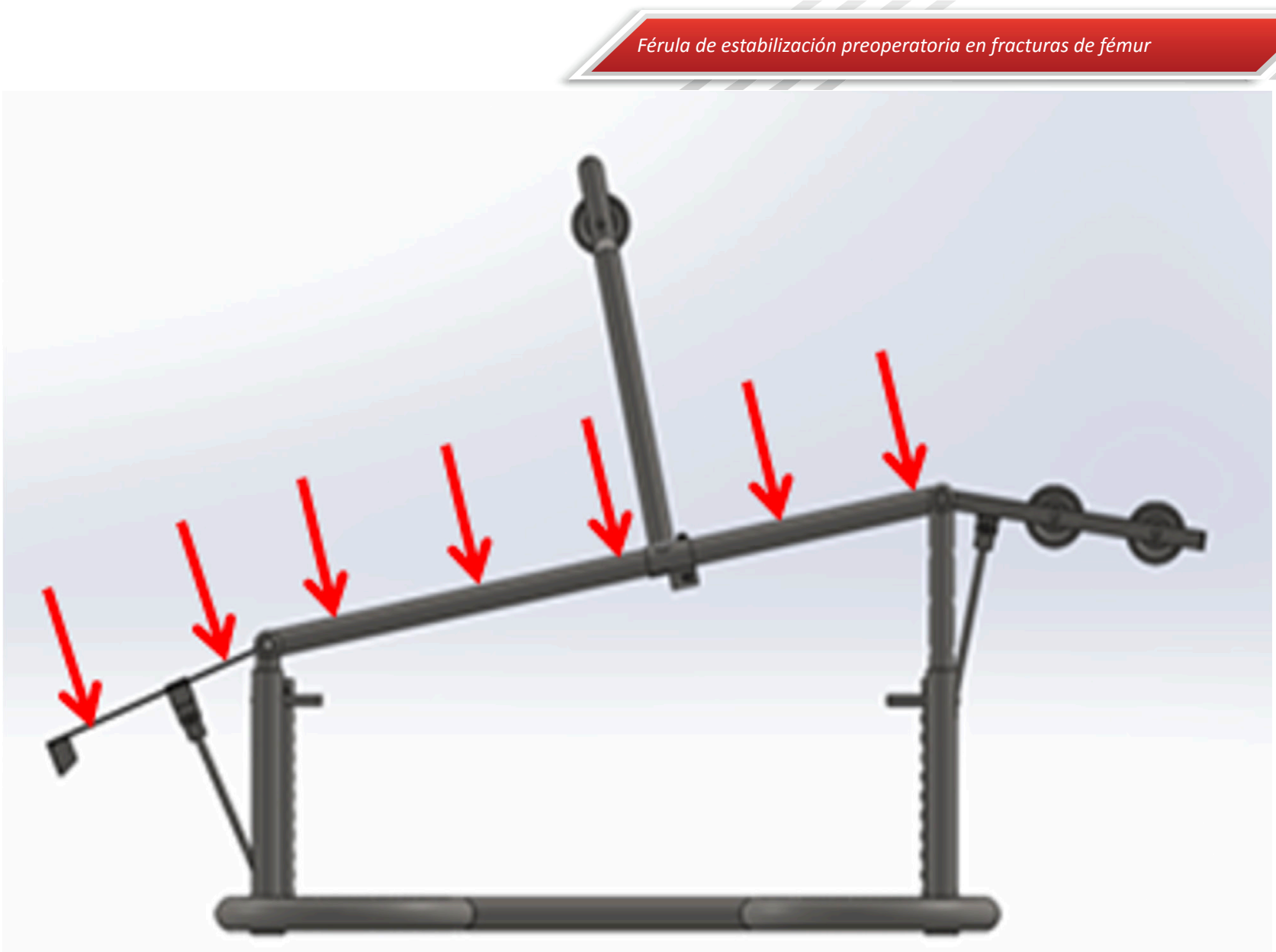

Fig. 4. Distribución de cargas en la férula.

El análisis de esfuerzos de los componentes que pueden presentar fallas, por sus dimensiones y las cargas a las que están sometidas, se realiza empleando un software basado en el Método de Elementos Finitos. La simulación se lleva a cabo aplicando cargas superiores, en magnitud, a las de operación; esto con la intención de garantizar la seguridad del dispositivo y comprobar que para las condiciones y fuerzas a las que estará sujeto en su uso no presentará fallas.

\section{Resultados}

Se desarrolla la simulación de esfuerzos para las dos posiciones que puede adoptar la férula. Los elementos se analizan separadamente con las respectivas condiciones de contorno (restricciones y cargas) enumerando los elementos de acuerdo con lo indicado en la Tabla 1. Al finalizar la sección, en la Tabla 3, se indican los resultados del factor de seguridad para los elementos analizados.

En la Fig. 5-a se muestra el resultado del análisis de la estructura base de la férula (18); así mismo en la Fig 5-b se puede observar el detalle de las zonas más esforzada, mientras que en la Fig. 5-c se indican la escala de esfuerzos de von Mises para el elemento estructural. 


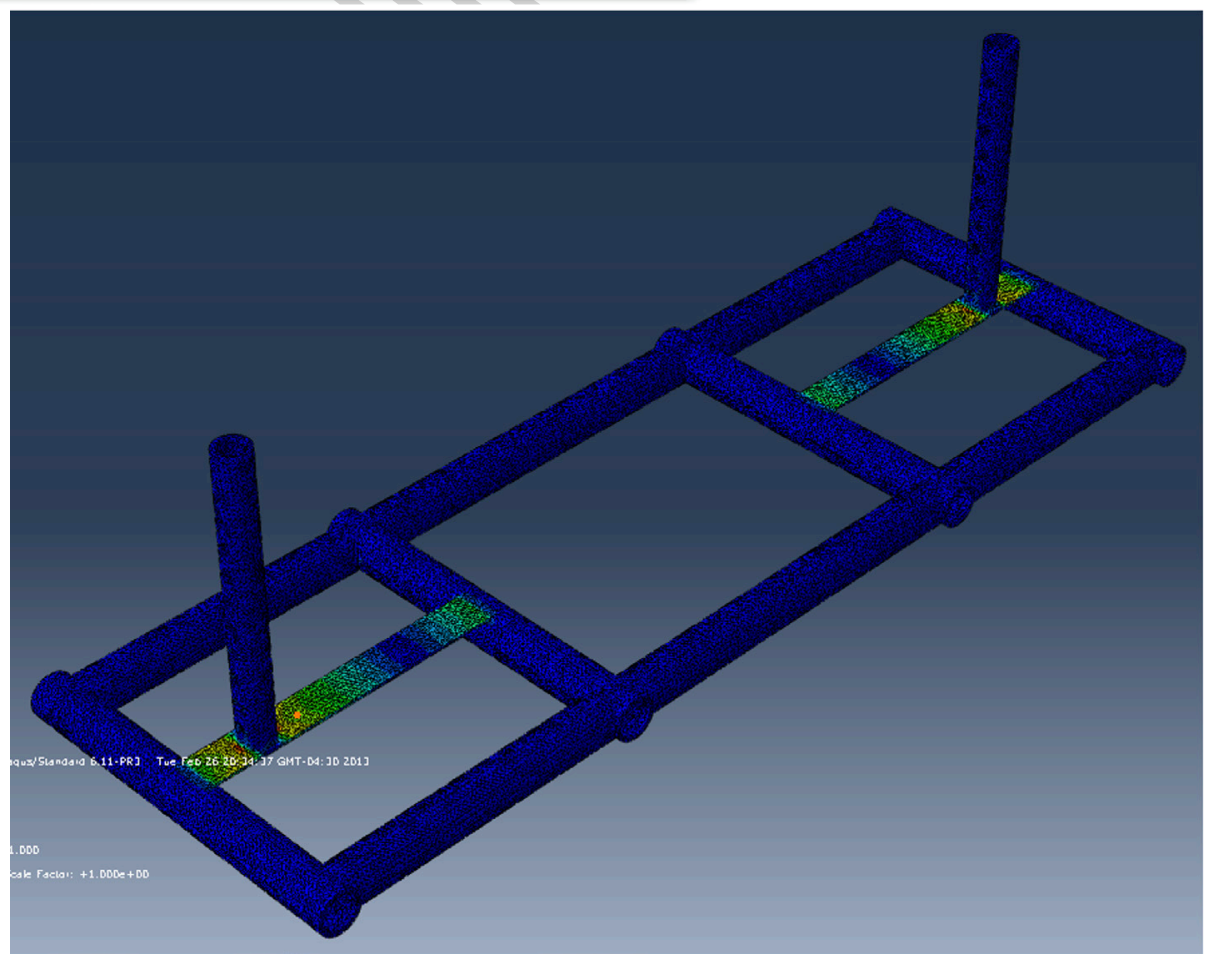

(a)

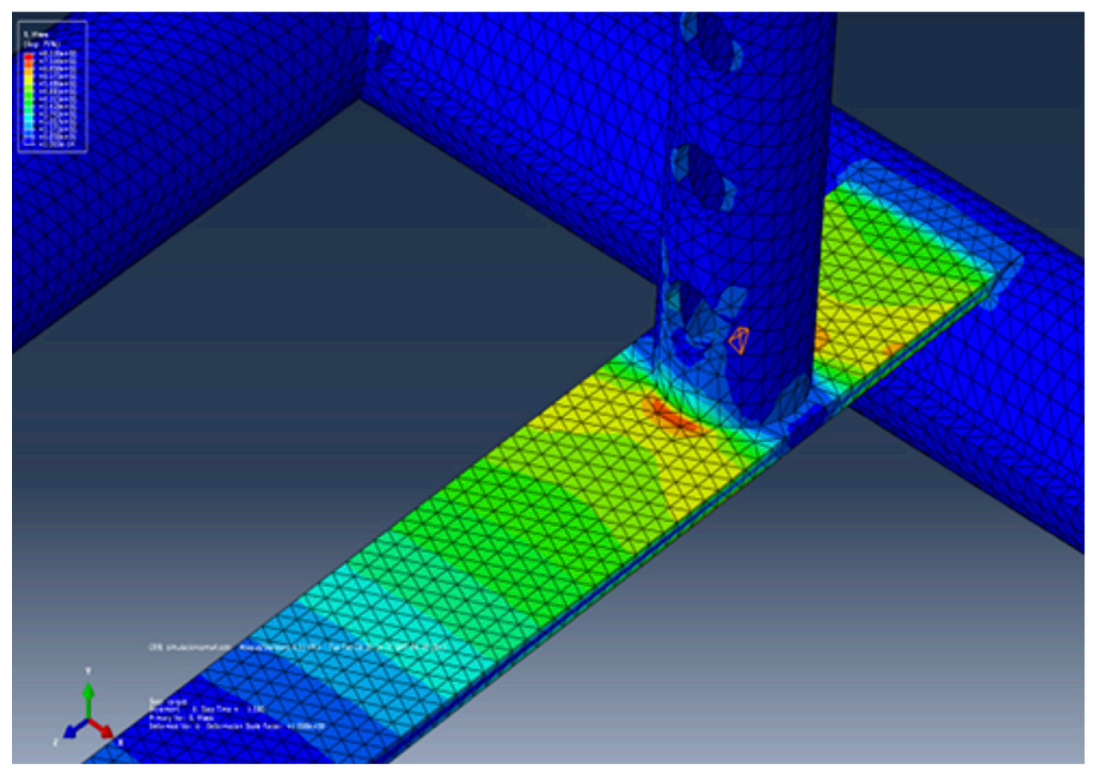

(b)

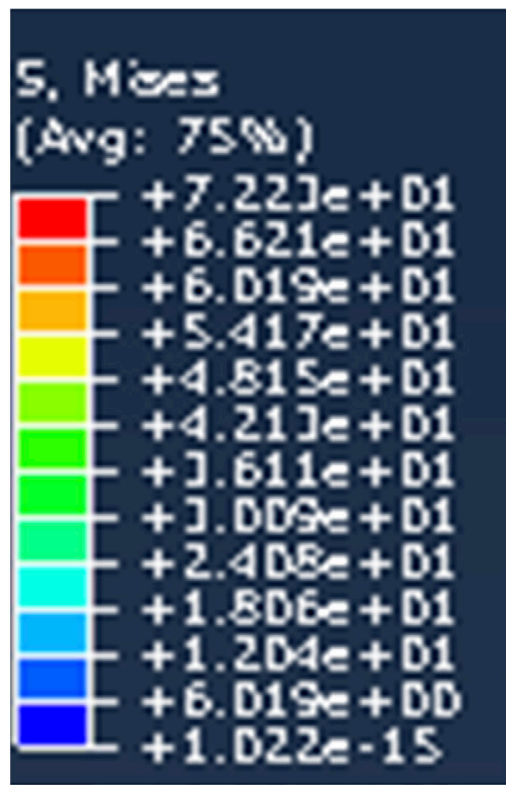

(c)

Fig. 5. Distribución de esfuerzos de von Mises (MPa) en la estructura base de la férula, (a) Vista isométrica de la base $m$ (b) Detalle de la zona más esforzada, (c) Escala de distribución de esfuerzos de von Mises $(\mathrm{MPa})$.

Para analizar los elementos de soporte, se presenta el conjunto columnas-eje (1), para la posición Nro. 1, el cual se analiza sujeto a una carga distribuida en el centro del eje. En la Fig. 6-a se muestra el resultado del análisis de la estructura conjunto columnas-eje (1); así mismo en la Fig 6-b se muestra el detalle de las zonas más esforzada, mientras que en la Fig. 6-c se observa la escala de esfuerzos de von Mises para el elemento estructural. 


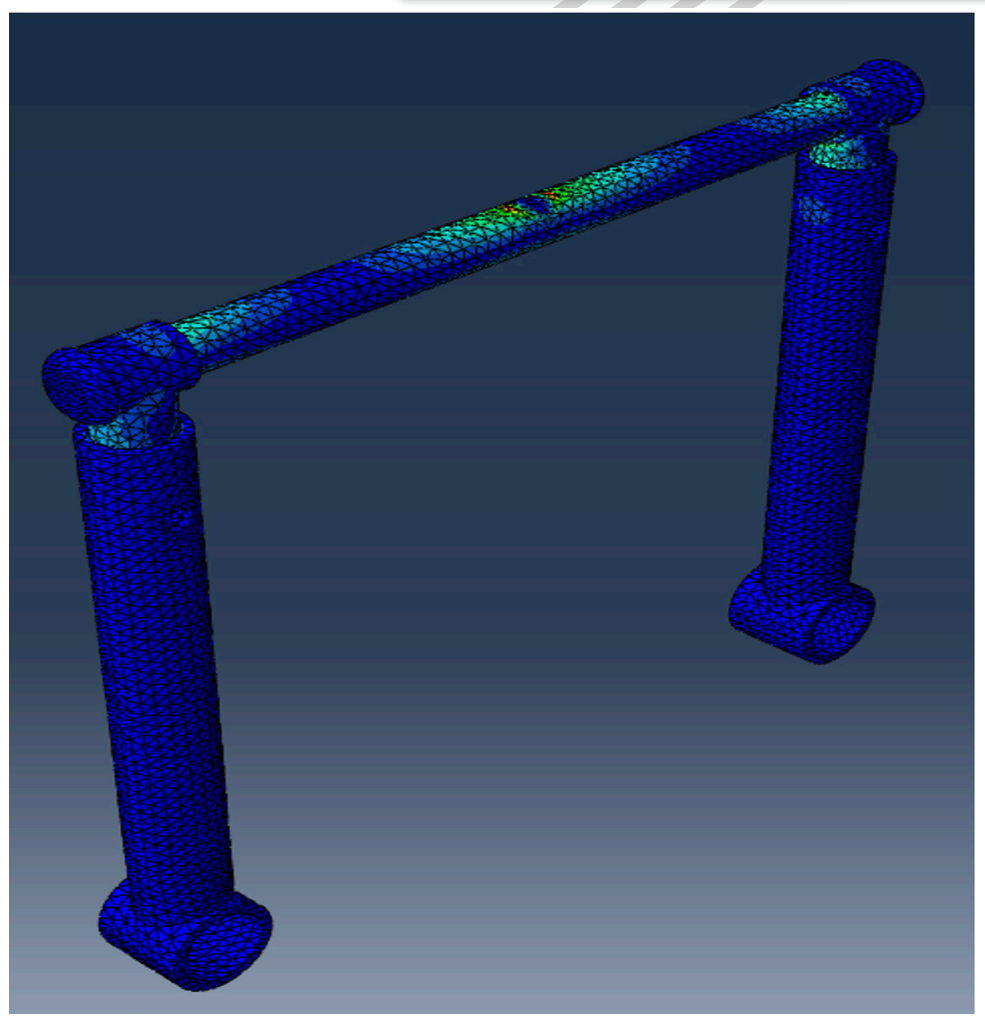

(a)

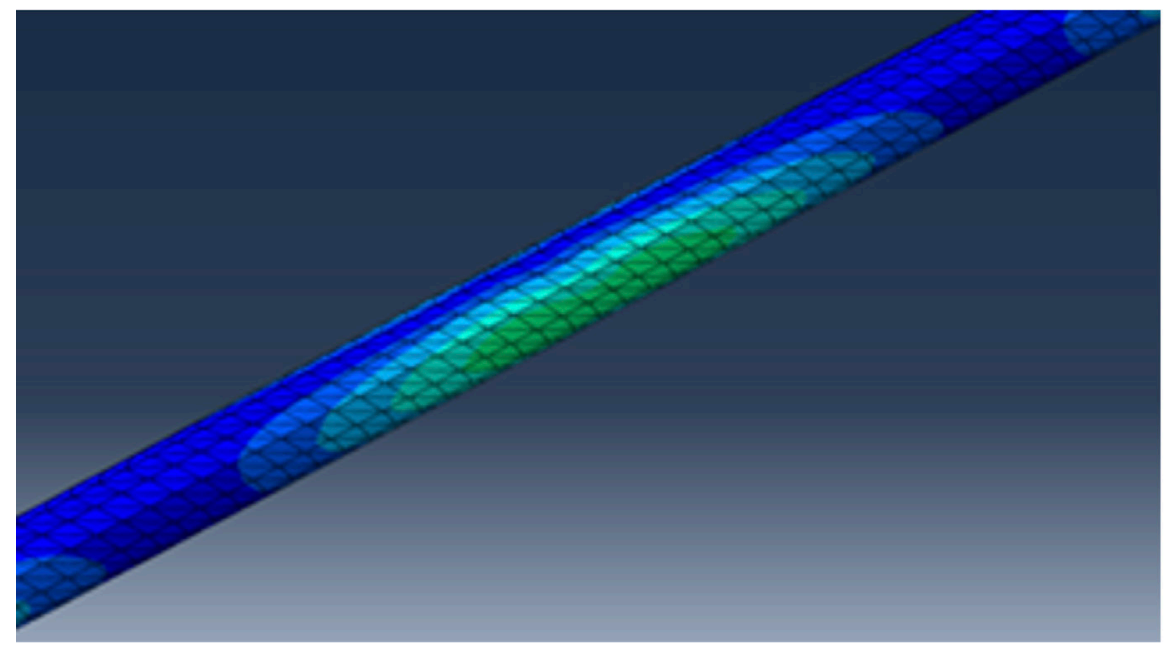

(b)

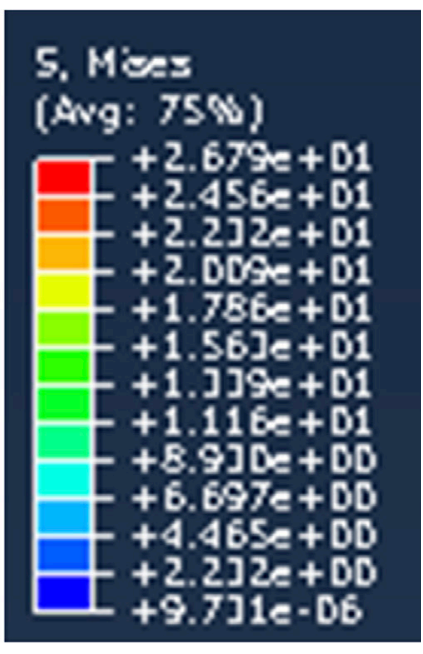

(c)

Fig. 6. Distribución de esfuerzos de von Mises (MPa) en el conjunto columnas-eje en la posición Nro. 1 (a) Vista isométrica del conjunto (b) Detalle de la zona más esforzada, (c) Escala de distribución de esfuerzos de von Mises (MPa).

Por otra parte, en la Fig. 7-a se muestra el resultado del análisis de la estructura conjunto columnas-eje (1) para la posición Nro. 2; así mismo en la Fig 7-b se muestra el detalle de las zonas más esforzada, mientras que en la Fig. 7-c se observa la escala de esfuerzos de von Mises para el elemento estructural en la posición correspondiente 


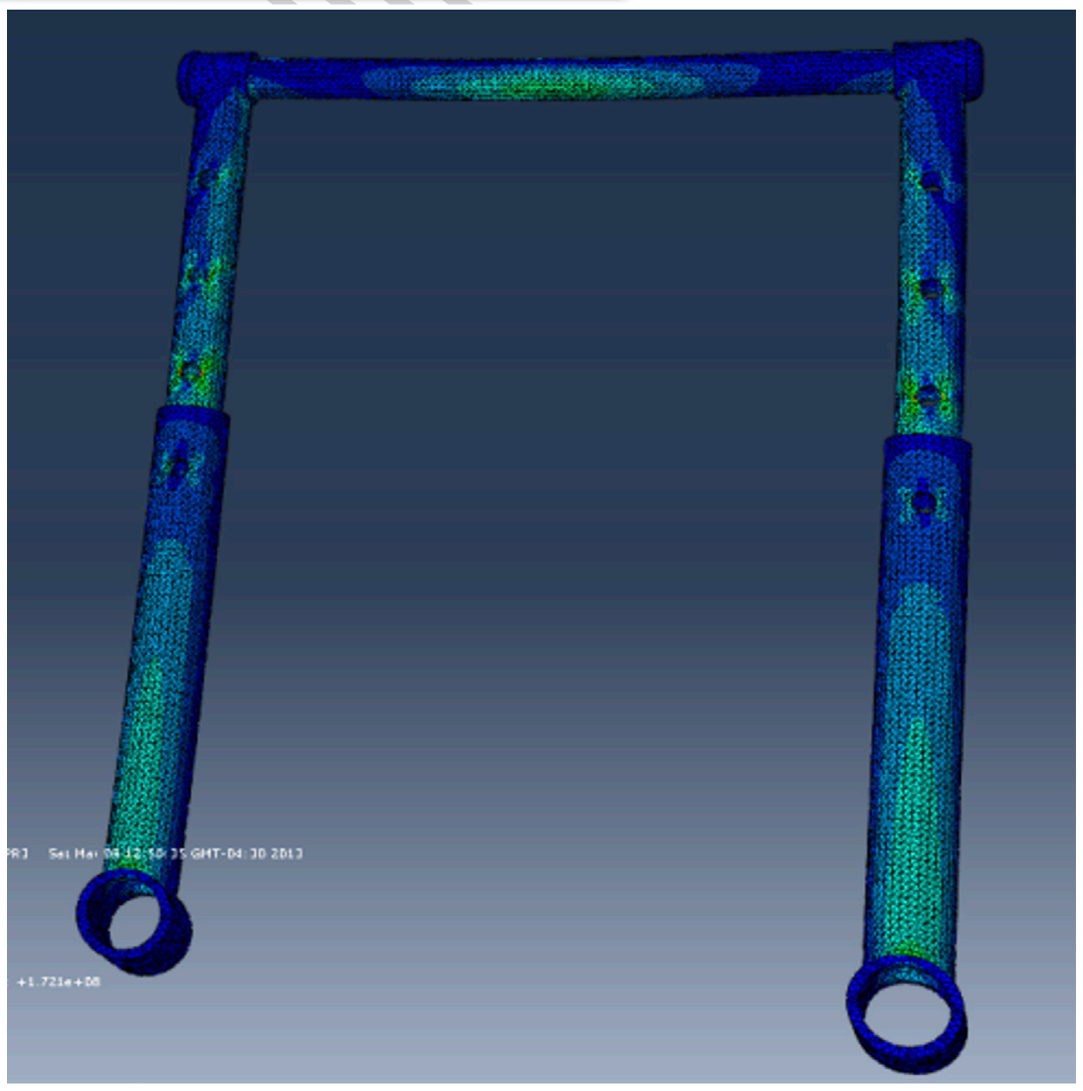

(a)

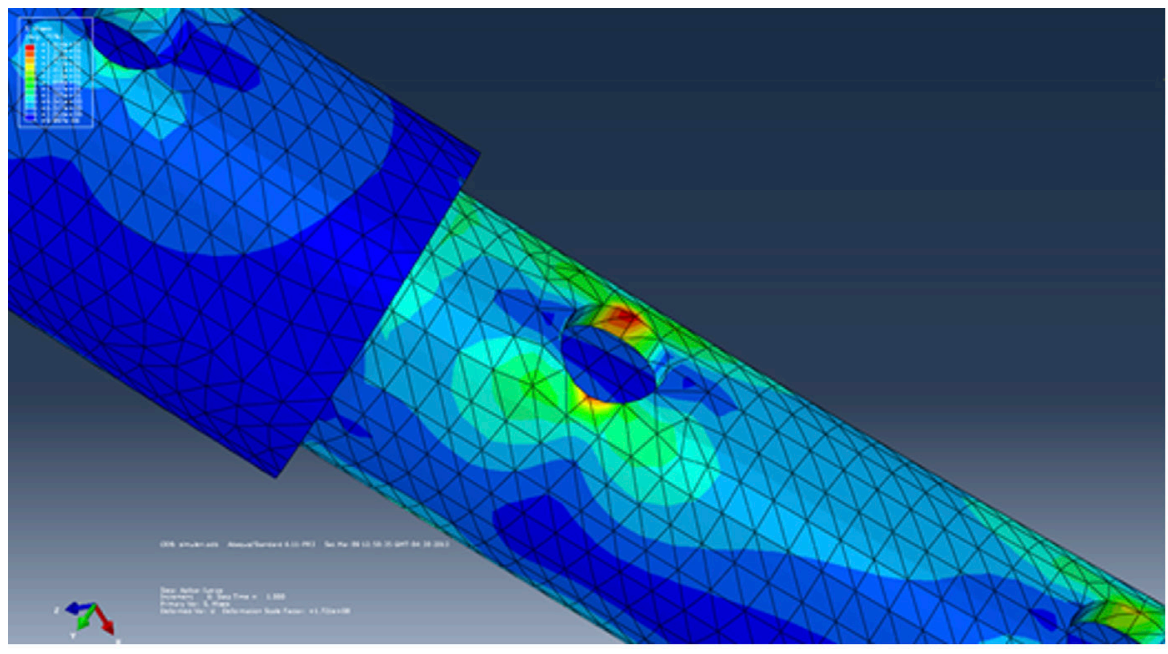

(b)

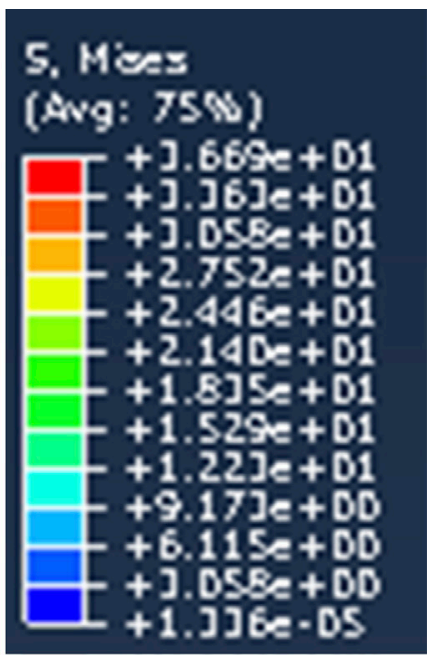

(c)

Fig. 7. Distribución de esfuerzos de von Mises (MPa) en el conjunto columnas-eje en la posición Nro. 2 (a) Vista isométrica del conjunto (b) Detalle de la zona más esforzada, (c) Escala de distribución de esfuerzos de von Mises (MPa).

Adicionalmente, se lleva a cabo el análisis de los pasadores que forman parte del sistema de regulación de la elevación a la cual se coloca la pantorrilla del paciente para ejercer la tracción adecuada, según el tratamiento a aplicar. En la Fig. 8-a se muestra el detalle de las zonas más esforzada, mientras que en la Fig. 8-b se observa la escala de esfuerzos de von Mises para el elemento sujeto a esfuerzos cortantes 


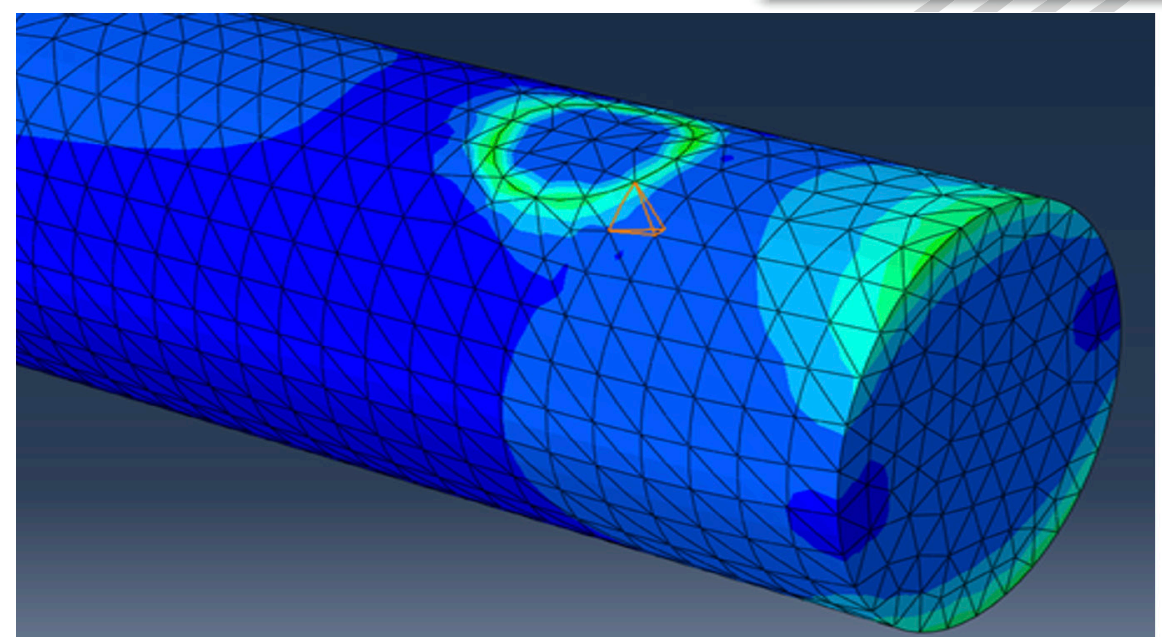

(a)

\section{Mienz (Ang: 75N)}

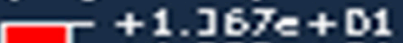

$++1.25] \mathrm{e}+\mathrm{D1}$

$-+1.1 \mathrm{Jge}+\mathrm{D1}$

$-+1.025 e+D 1$

- +9.114e+DD

$+7.975 \mathrm{e}+00$

$-+6.8 \mathrm{Se}+\mathrm{DD}$

$+5.696=+00$

$+4.557 \mathrm{e}+0 \mathrm{D}$

$+] .418=+D D$

$+2.278 \mathrm{D}+\mathrm{DD}$

$+1.1 \mathrm{Jg}=+\mathrm{DD}$

+1 . DSAe-D6

(b)

Fig. 8. Distribución de esfuerzos de von Mises (MPa) en el pasador (a) Detalle de la zona más esforzada, (b) Escala de distribución de esfuerzos de von Mises (MPa).

La tubería para unión de columnas (10) tiene como función sujetar, mediante abrazaderas, a los ejes y funciona como la base donde se deben colocar las telas y/o gasas para vestir a la férula en la zona donde descansa la pantorrilla. En la Fig. 9-a se muestra el resultado del análisis de este elemento en la posición Nro. 1, cargado en su centro geométrico; así mismo en la Fig. 9-b se muestra el detalle de las zonas más esforzadas, mientras que en la Fig. 9-c se observa la escala de esfuerzos de von Mises para el elemento estructural. En el mismo orden, en la Fig. 10, se muestran los resultados de esta tubería cuando la férula adopta la posición Nro. 2.

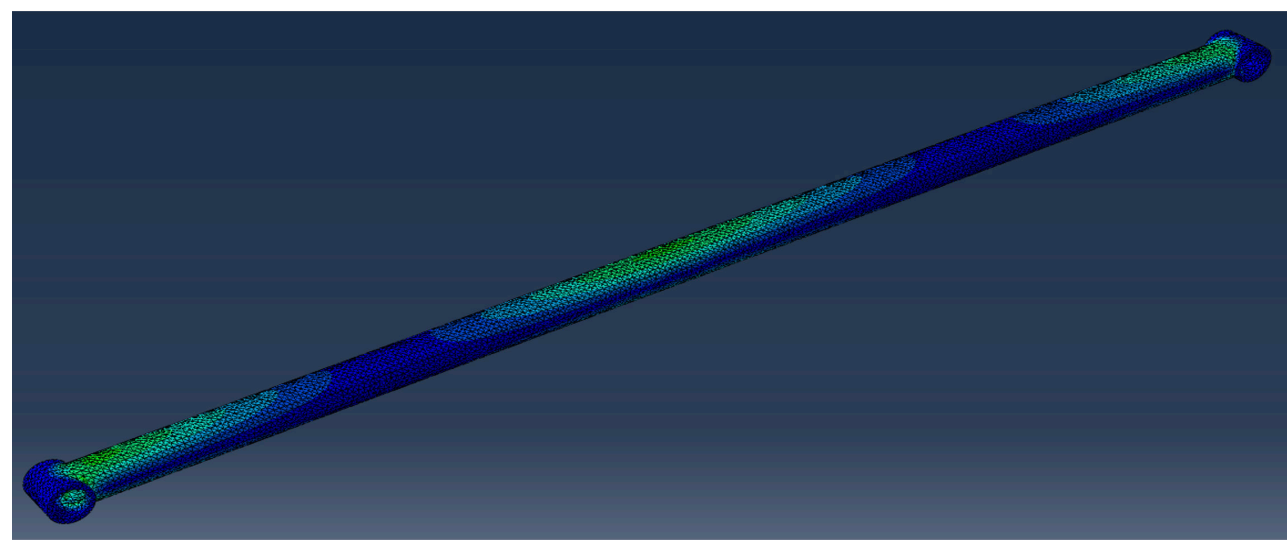

(a) 


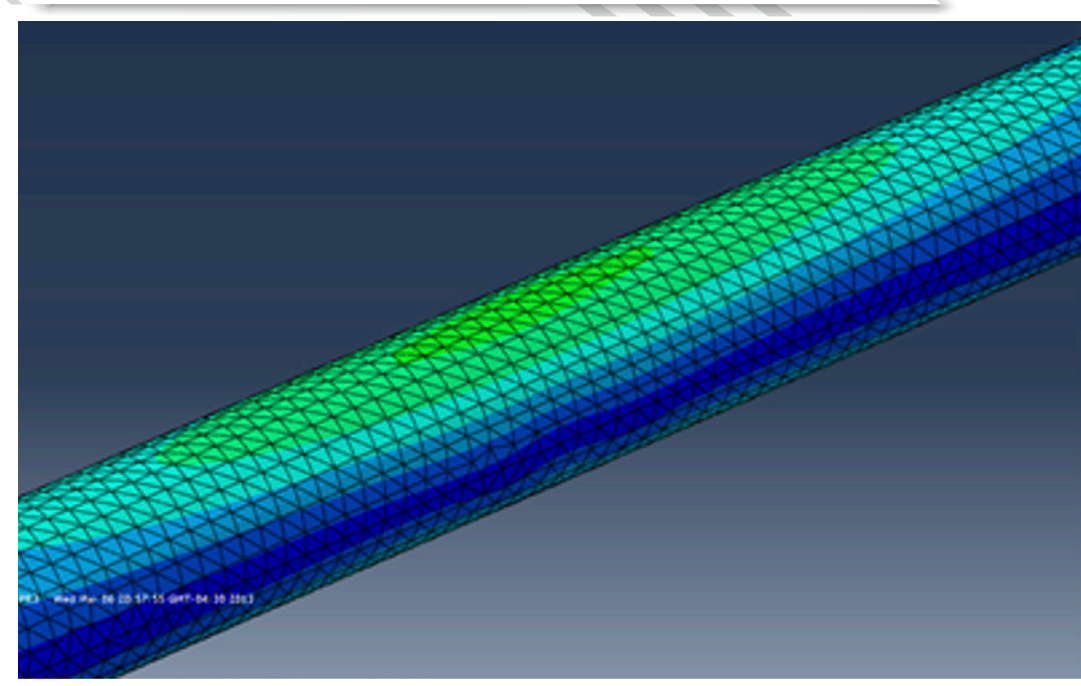

(b)

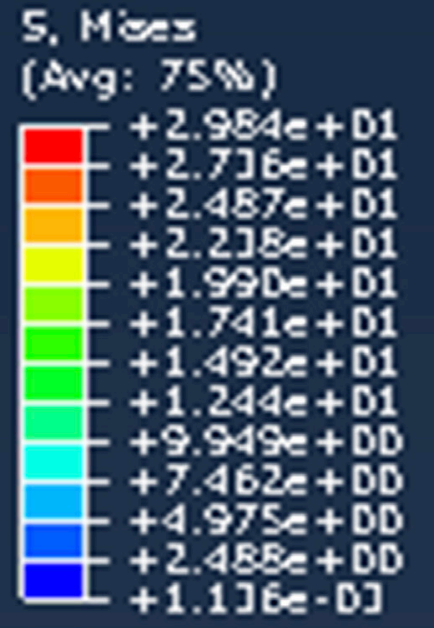

(c)

Fig. 9. Distribución de esfuerzos de von Mises (MPa) en tubería de unión de columnas en la posición Nro. 1 (a) Vista isométrica de la tubería de unión (b) Detalle de la zona más esforzada, (c) Escala de distribución de esfuerzos de von Mises (MPa).

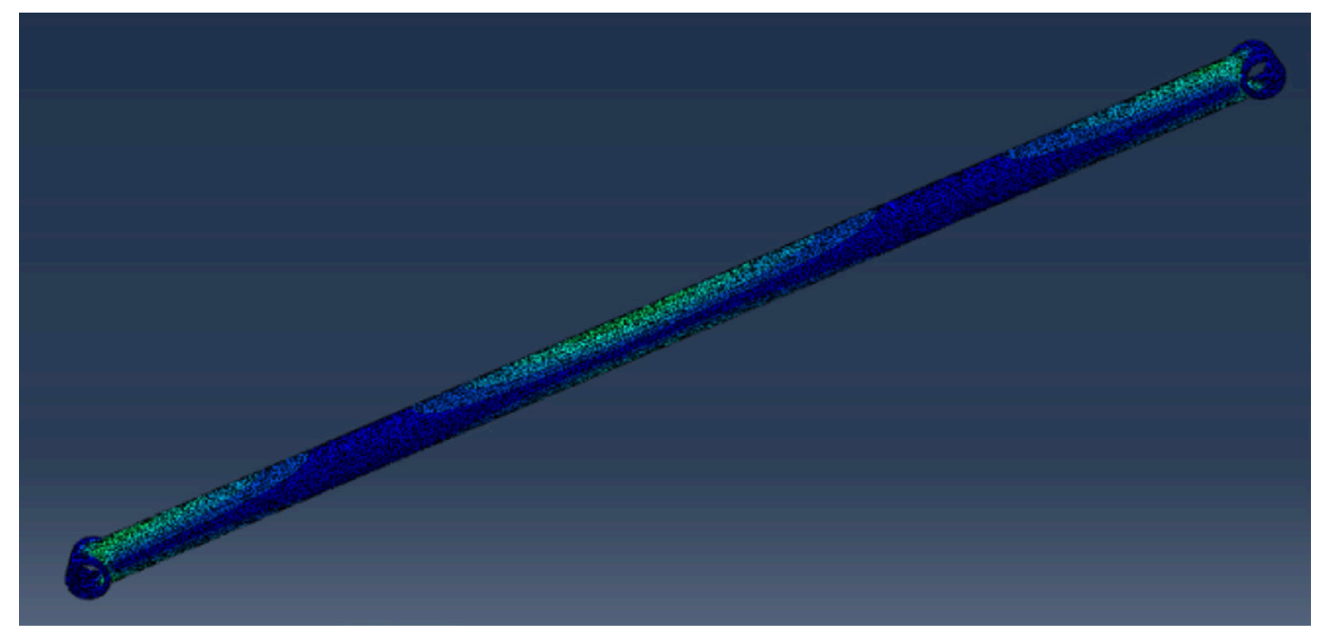

(a)

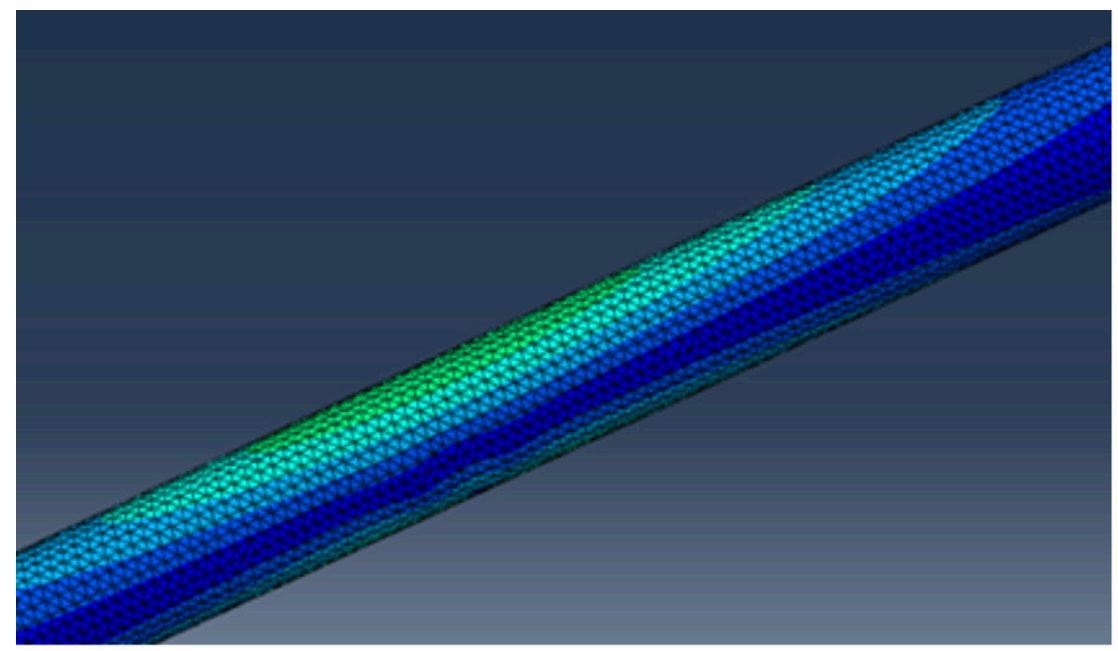

(b)

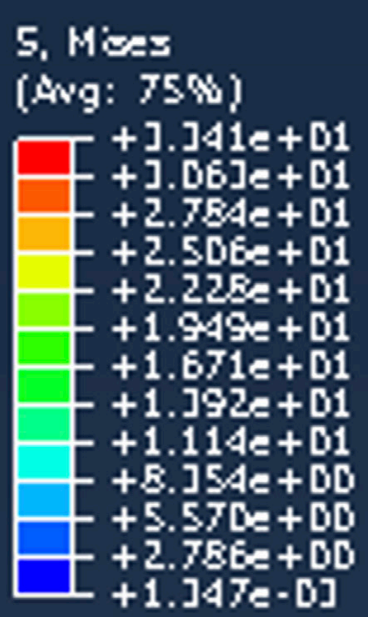

(c)

Fig. 10. Distribución de esfuerzos de von Mises (MPa) en tubería de unión de columnas en la posición Nro. 2 (a) Vista isométrica de la tubería de unión (b) Detalle de la zona más esforzada, (c) Escala de distribución de esfuerzos de von Mises (MPa). 
El posa muslo (3) diseñado a partir de láminas de acero inoxidable 304 de 1,5 mm de espesor, cortadas y soldadas que cumple la función de sostener al muslo, carga para la cual se analiza. En la Fig. 11-a se muestra el resultado del análisis del posa muslo, cargado en su centro geométrico; mientras que la Fig 11-b se muestra el detalle de las zonas más esforzada y en la Fig. 11-c se observa la escala de esfuerzos de von Mises para el elemento de soporte.

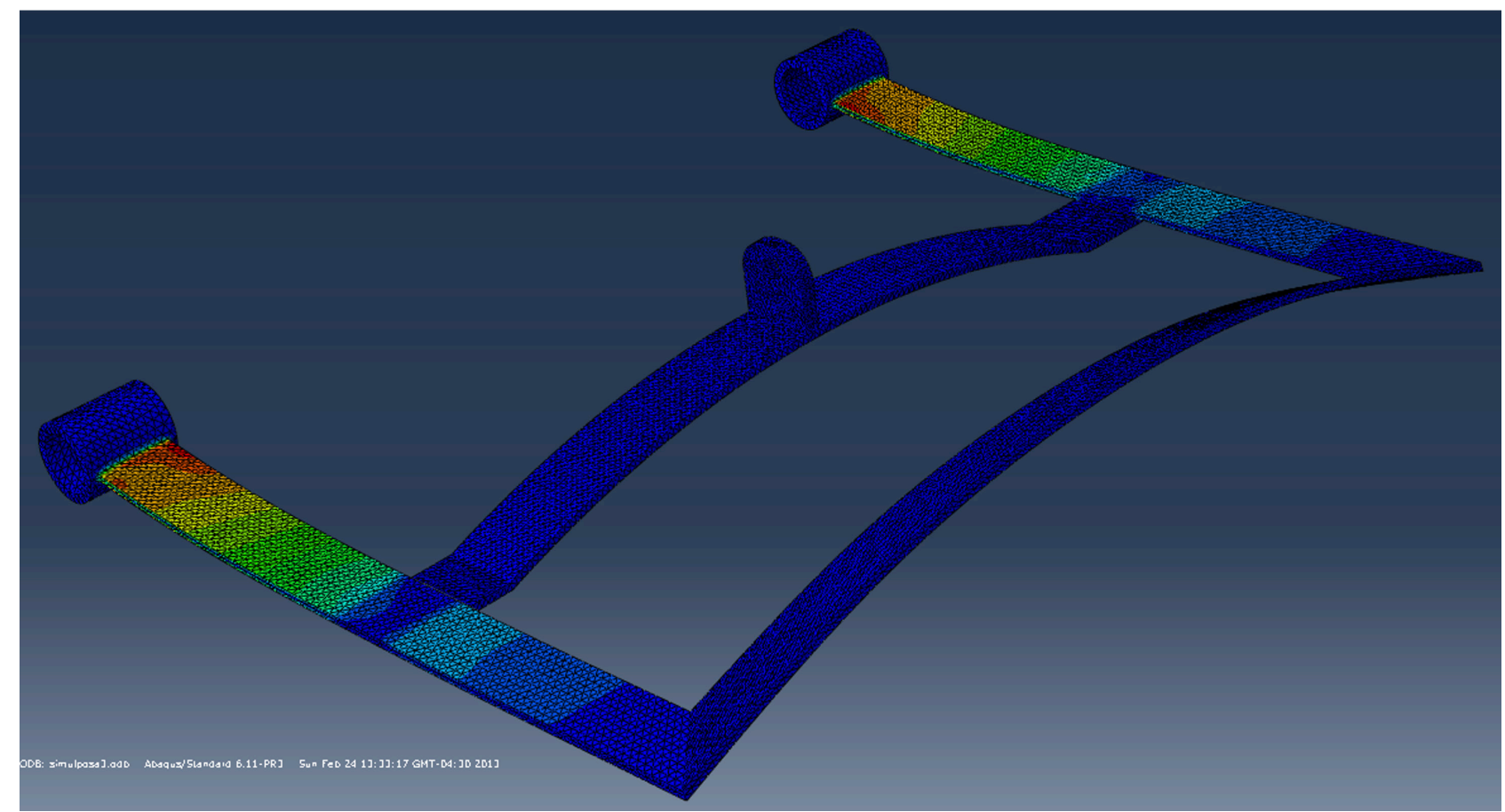

(a)

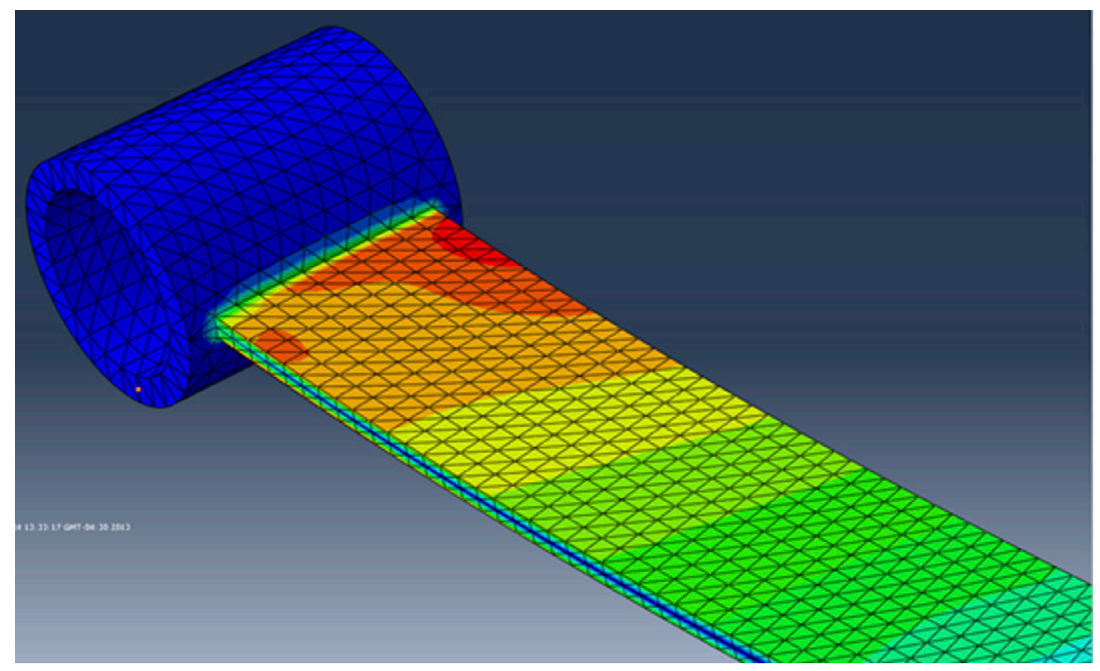

(b)

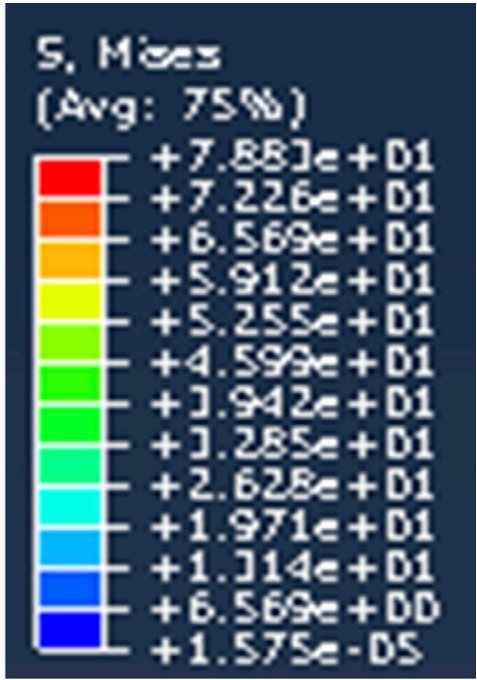

(c)

Fig. 11. Distribución de esfuerzos de von Mises (MPa) en el posa muslo (a) Vista isométrica del posa muslo (b) Detalle de la zona más esforzada, (c) Escala de distribución de esfuerzos de von Mises (MPa).

En la Fig. 12 se observa los resultados del análisis de esfuerzo del gancho (13) cuya función es regular la elevación de la pierna y llevar a cabo la tracción, en conjunto con las tuberías con agujeros que están soldadas a la estructura base. 


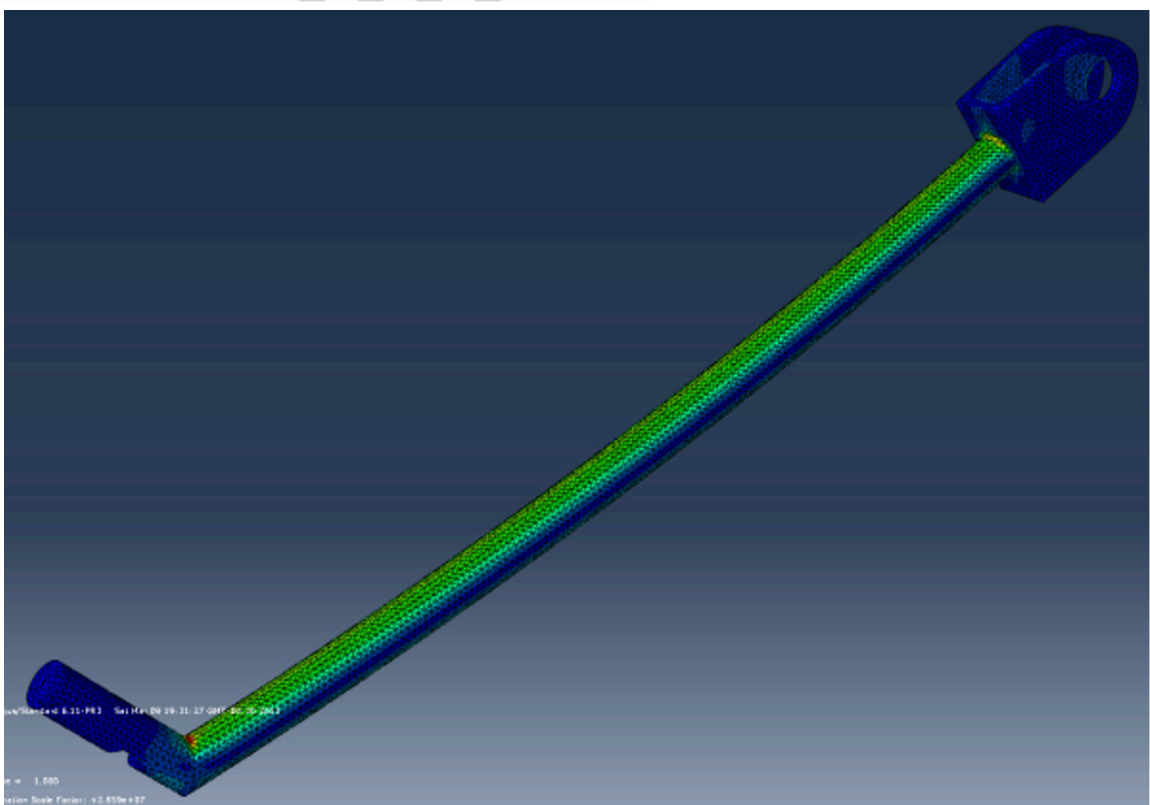

(a)

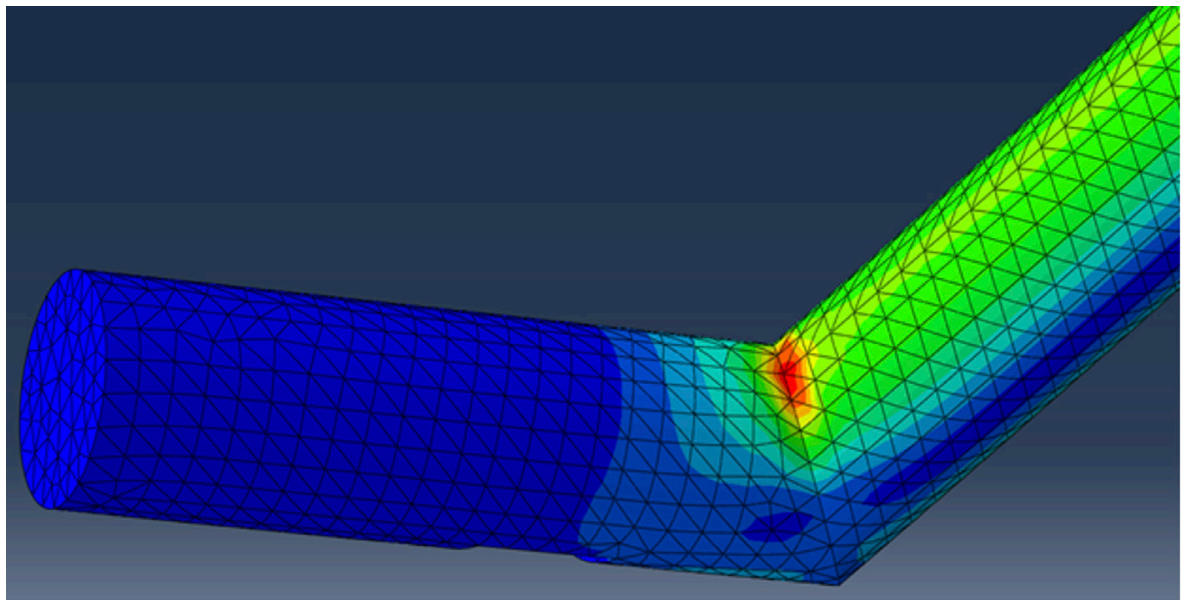

(b)

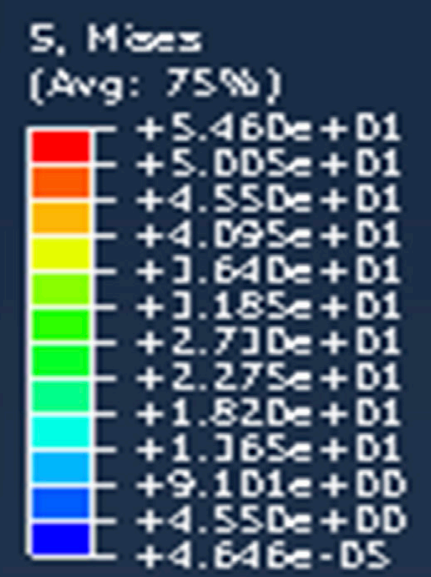

(c)

Fig. 12. Distribución de esfuerzos de von Mises (MPa) en el gancho de la férula (a) Vista isométrica del gancho (b) Detalle de la zona más esforzada, (c) Escala de distribución de esfuerzos de von Mises (MPa).

Finalmente, en las Fig. 13 y 14 se muestran los resultados del análisis de los esfuerzos a los cuales se encuentra sometida la campana (8) para las dos posiciones que puede adoptar la férula. Esta pieza funciona como elemento principal de tracción, ya que la polea principal, que se ubica sobre dicho elemento, es la encargada de ejercer la tracción directa sobre la fractura. 


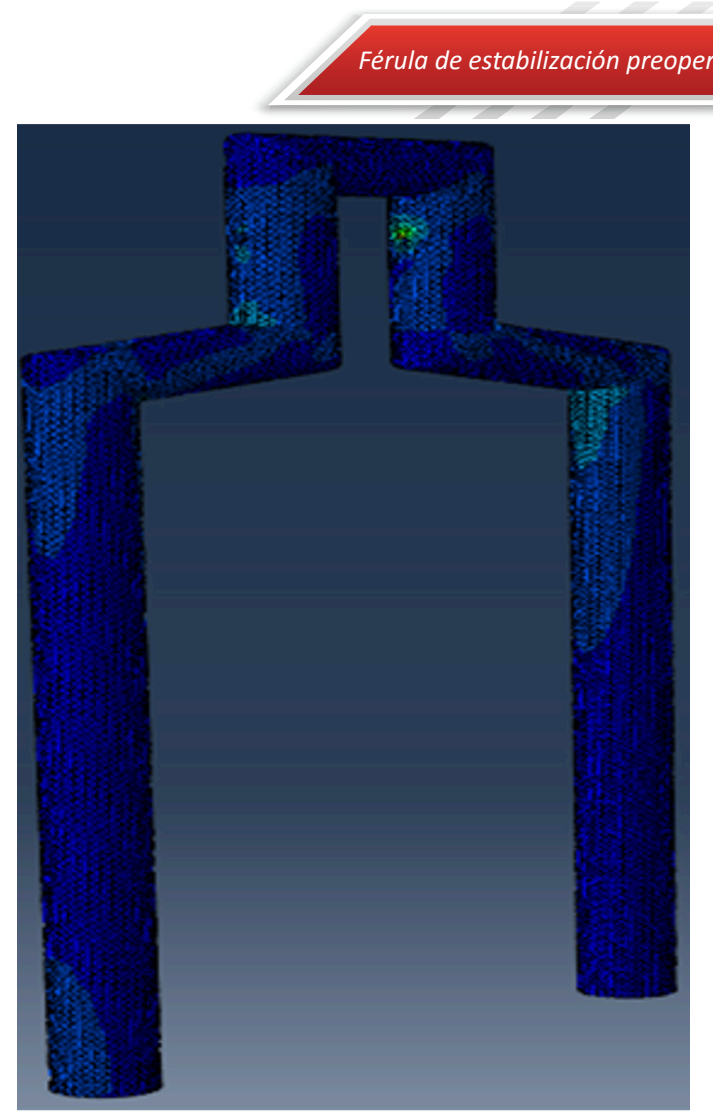

(a)

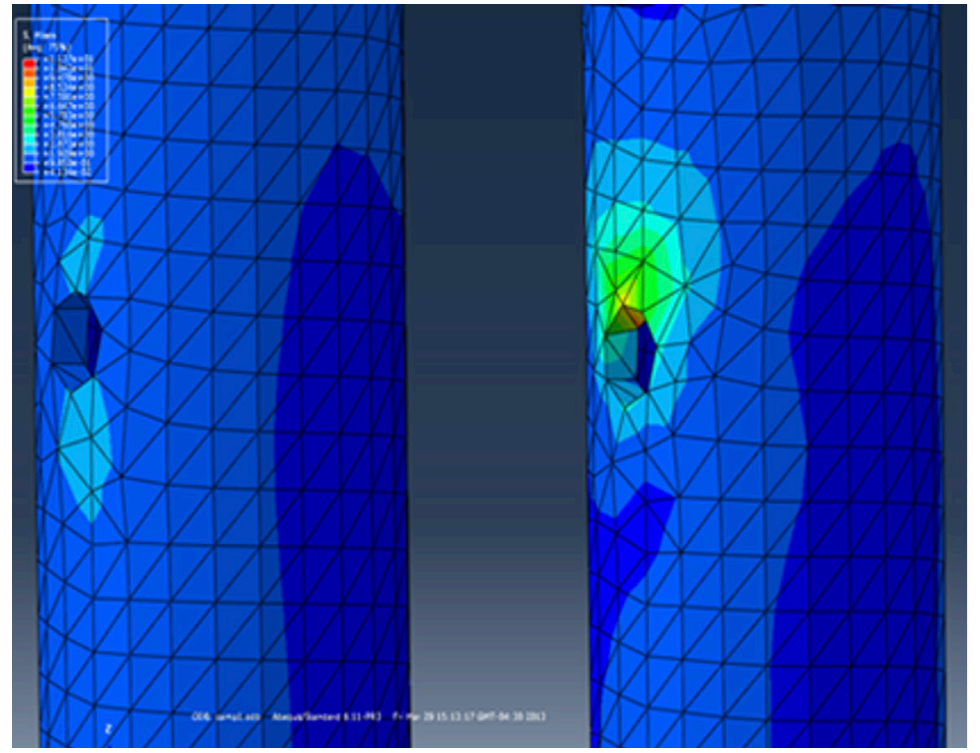

(b)

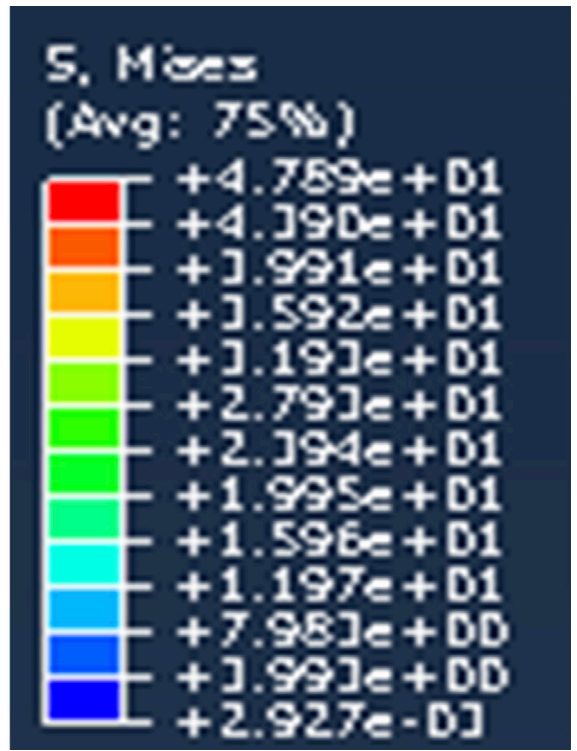

(c)

Fig. 13. Distribución de esfuerzos de von Mises (MPa) para la campana en la posición Nro. 1 (a) Vista isométrica de la campana, (b) Detalle de la zona más esforzada, (c) Escala de distribución de esfuerzos de von Mises (MPa).

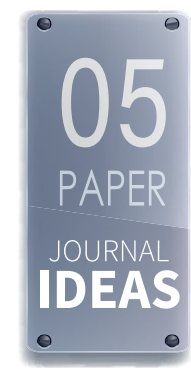




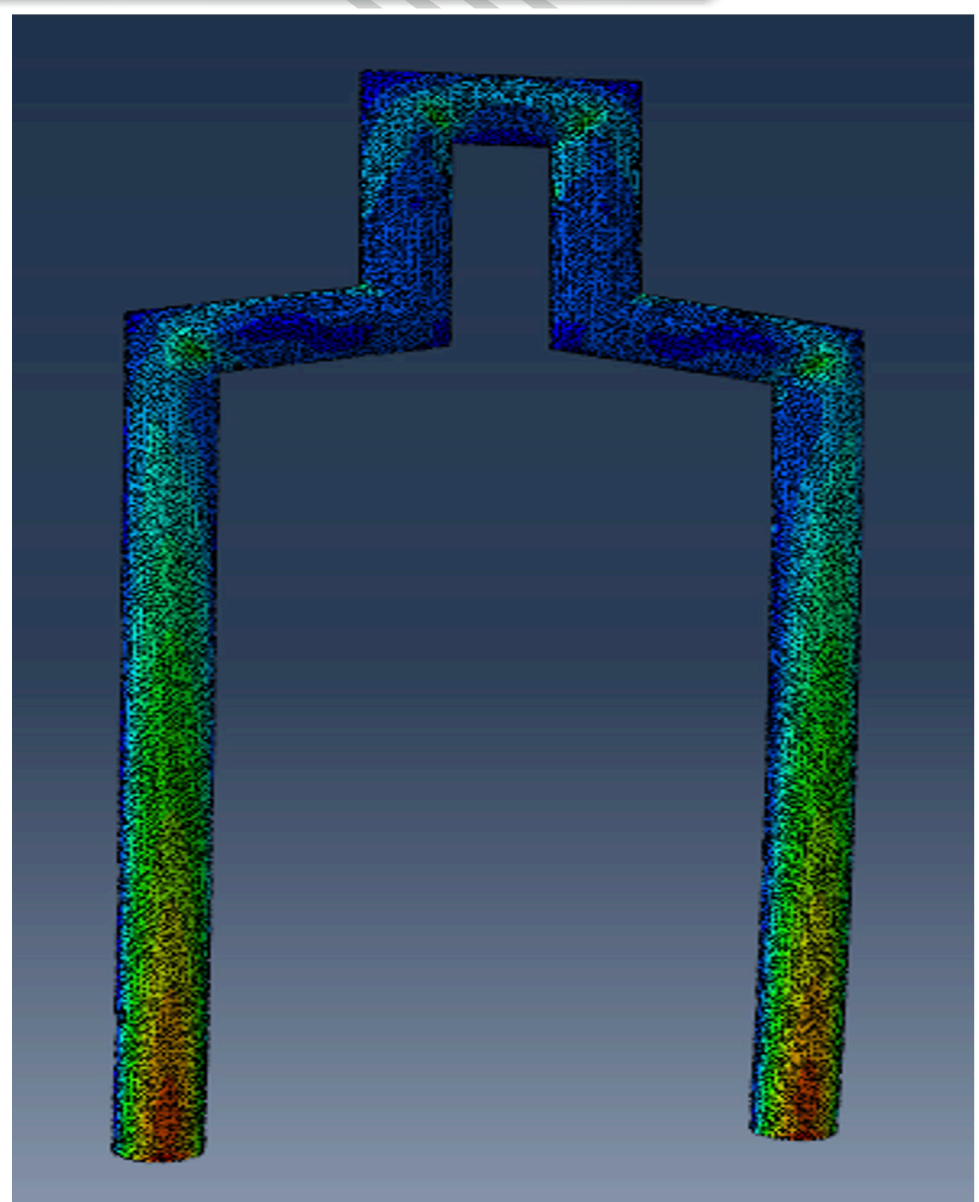

(a)

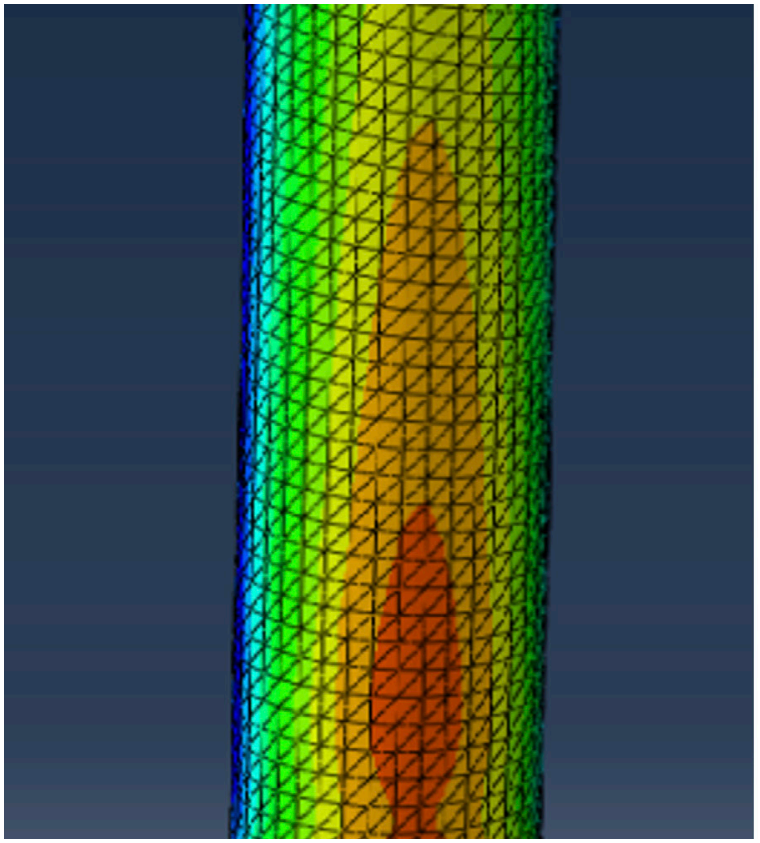

(b)

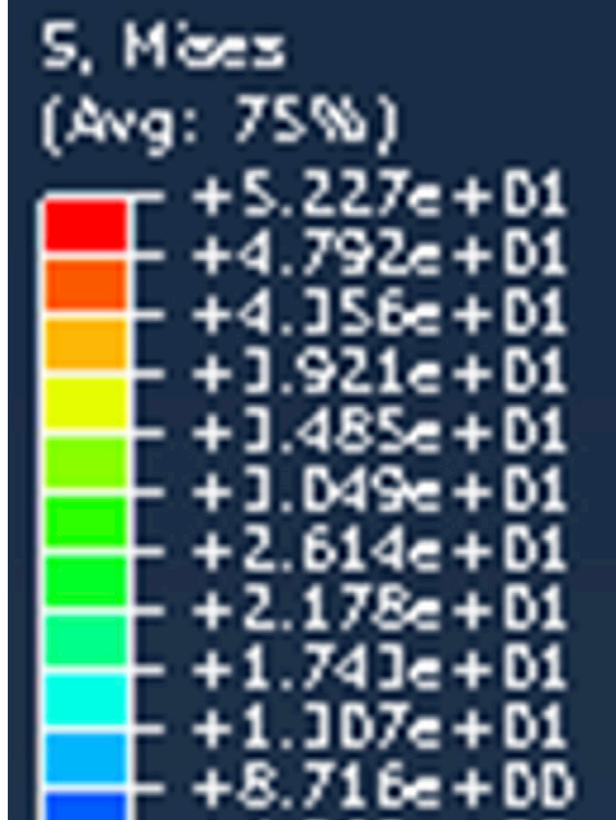

(c)

Fig. 14. Distribución de esfuerzos de von Mises (MPa) para la campana en la posición Nro. 2 (a) Vista isométrica de la campana, (b) Detalle de la zona más esforzada, (c) Escala de distribución de esfuerzos de von Mises (MPa). 
Tabla 3. Factor de seguridad para las piezas analizadas

\begin{tabular}{|c|c|c|}
\hline Elemento & $\begin{array}{c}\text { Esfuerzo Máximo } \\
(\mathbf{M P a})\end{array}$ & Factor de seguridad \\
\hline Estructura base & 72,23 & 2,84 \\
\hline Eje & 23,95 & 8,55 \\
\hline Ensamble columnas-eje & 36,56 & 5,61 \\
\hline Pasador & 14,28 & 14,36 \\
\hline Tuberías de unión de columnas & 26,46 & 7,75 \\
\hline Posa muslo & 81,91 & 2,50 \\
\hline Gancho & 56,56 & 3,62 \\
\hline Campana & 47,89 & 4,28 \\
\hline
\end{tabular}

\section{Conclusiones y trabajos futuros}

El diseño propuesto fue analizado mediante el programa computacional ABAQUS/CAE. Los resultados obtenidos de la simulación realizada comprobaron que el dispositivo resiste los estados de carga a los que será sometido durante su operación.

Los factores de seguridad de cada pieza crítica analizada son valores aceptables, mayores a 2,5, por lo que se asegura que el conjunto armado no va a presentar fallas si sus piezas estudiadas de forma individual no sufren deformación.

El diseño es estético y cumple con las especificaciones sanitarias requeridas, ya que puede ser usado más de una vez por distintos pacientes, es de fácil limpieza y es resistente a la corrosión.

El diseño es capaz de resistir las cargas de un miembro inferior en descanso en diferentes posiciones de acuerdo con el tipo de tracción que se aplique.

\section{Referencias}

Memarzadeh, A., Khadija Tissingh, E., Hull, P. y Trompeter, A. Intramedullary nailing of femoral shaft fractures in adults. Orthopaedics and Trauma, Volume 31, Issue 2, 2017, Pages 86-92, ISSN 1877-1327.

Etxebarría-Foronda I , Caeiro-Rey JR. Utilidad de la tracción preoperatoria en la fractura de cadera. Rev Osteoporos Metab Miner. 2018;10(2):98-102

García-Alvarez G. Desarrollo histórico de la traumatología y de la cirugía ortopédica a partir del siglo XV. Revista Española de Investigaciones Quirúrgicas. Volumen 20, Nro. 3, 2017, Pages 103-110.

Algarra, L; Sánchez, J; Gámez, B; Valera, Luis. Diseño de una férula de tracción. Revista INGENIERÍA UC, vol. 20, núm. 2, mayo-agosto, 2013, pp. 7-13 
Bumpass, D. B., Ricci, W. M., McAndrew, C. M., \& Gardner, M. J. (2015). A prospective study of pain reduction and knee dysfunction comparing femoral skeletal traction and splinting in adult trauma patients. Journal of orthopaedic trauma, 29(2), 112-118.

Budynas, R. G y Nisbett, K. J. Shigley's Mechanical Engineering Design. (2019) McGraw-Hill Education

Even JL, Richards JE, Crosby CG, Kregor PJ, Mitchell EJ, Jahangir AA, Tressler MA, Obremskey WT. Preoperative skeletal versus cutaneous traction for femoral shaft fractures treated within 24 hours. J Orthop Trauma. 2012 Oct;26(10):e177-82. 